\title{
Hallux Malleus develops after Flexible Hallux Varus correction with Tensioned Suture Device: A Case Report
}

\author{
by Francis Chan, DPM ${ }^{1} \otimes$, Brent Wendel, DPM FACFAS $^{2} \otimes$
}

The Foot and Ankle Online Journal 5 (1): 2

Tensioned suture device has been described successfully for hallux varus corrections. A case report is presented of a flexible hallux varus correction with tensioned suture device. Transverse plane component of flexible hallux varus was successfully corrected; however, a previously mild extensor hallucis longus contracture worsened postoperatively and led to recurrence of hallux varus.

Key Words: Tension suture device, hallux varus, surgical complication.

Accepted: December, 2011

Published: January, 2012

This is an Open Access article distributed under the terms of the Creative Commons Attribution License. It permits unrestricted use, distribution, and reproduction in any medium, provided the original work is properly cited. (The Foot and Ankle Online Journal (www.faoj.org), 2011 All rights reserved.

$\mathrm{H}$ allux varus (HV) is most commonly seen as a complication of surgery, though it can present from a traumatic injury, scar contracture secondary to burn injury, systemic inflammatory arthritides and congenital malformation. ${ }^{1,2}$ The incidence of iatrogenic HV has been reported to be $2 \%$ to $15.4 \% .^{1-4}$ For iatrogenic $\mathrm{HV}$, multiple surgical steps have been attributed to its development: excision of fibular sesamoid, aggressive lateral collateral ligament release about the first metatarsophalangeal joint (MTPJ), excessive resection of first metatarsal medial eminence, overcorrection of intermetatarsal angle, excessive medial capsulorrhaphy and aggressive bandaging. ${ }^{1,2}$

Address correspondence to: Frances Chan, DP. Swedish Medical Center Podiatric Residency Program, Seattle, WA.

\footnotetext{
${ }^{1}$ Podiatric Resident Physician (PGY-2), Swedish Medical Center Podiatric Residency Program, Seattle, WA.

${ }^{2}$ Attending Physician, Swedish Medical Center Podiatric Residency Program, Seattle, WA.
}

Different techniques have been described for correction for $\mathrm{HV}$, such as abductor hallucis release, extensor hallucis longus (EHL) transfer, EHL release, phalangeal osteotomy, first metatarsal osteotomy and first MTPJ arthrodesis. ${ }^{3-8}$ Recently, tensioned suture device (TSD) has become more utilized in foot and ankle surgery. Several articles have demonstrated adequate correction of $\mathrm{HV}$ using TSD. ${ }^{6,7,9}$ Complications have not been described with use of TSD about the first MTPJ but complications have been described when used in ankle fracture repairs. Knot and button irritation, foreign body reaction with poorly healing wounds, infection and loosening of TSD secondary to osteolysis have been described. ${ }^{10-12}$

This case report is presented to discuss use of TSD to correct the transverse plane deformity of HV, while a sagittal plane deformity worsened postoperatively. 

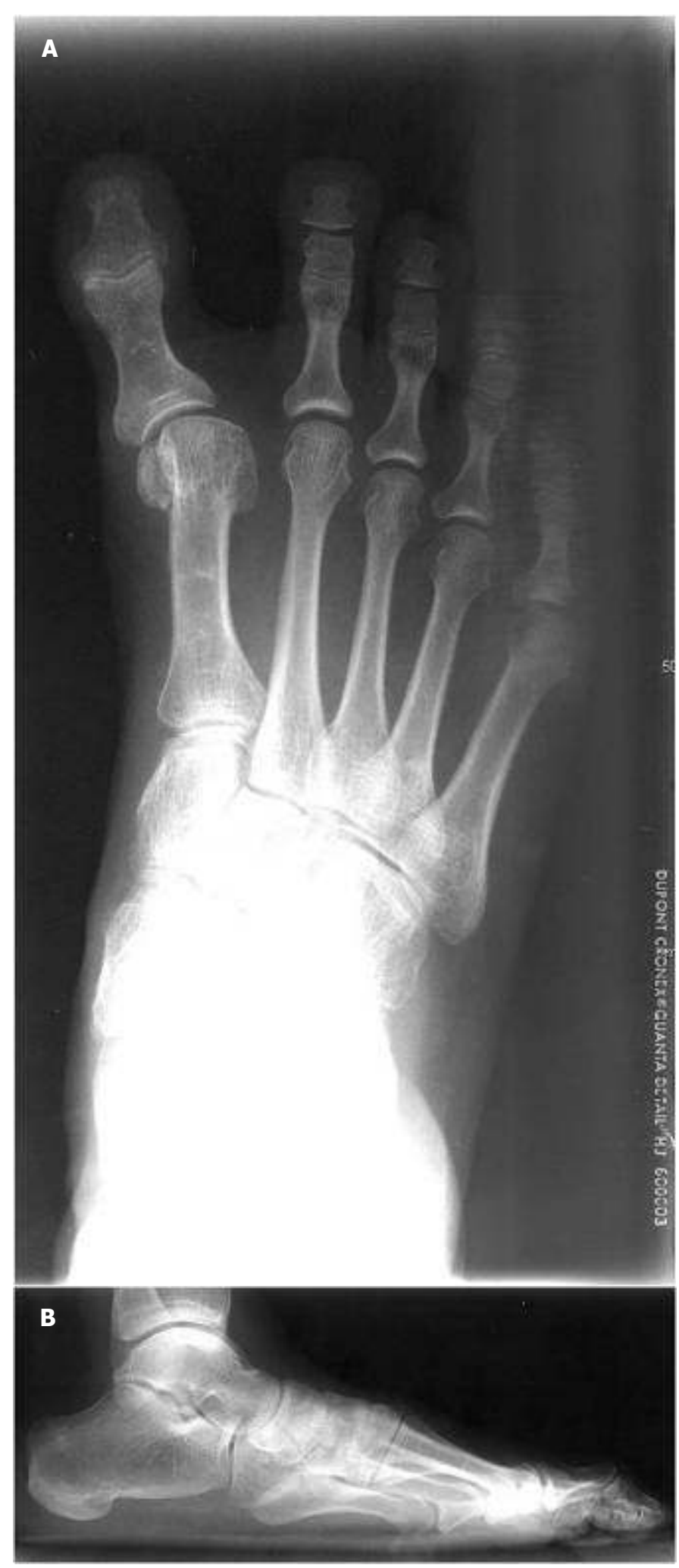

Figure 1A and 1B Preoperative radiograph of right foot. Dorsal Plantar (DP) view showing $20.5^{\circ}$ hallux abduction angle. (A) Lateral view, mild hallux malleus. (B)

\section{Case report}

A 46 year-old female presented with bilateral hallux pain and difficulty fitting into shoes. She previously received right bunionectomy 25 years ago by another physician, which included fibular sesmoidectomy. (Fig $1 \mathrm{~A}$ and $1 \mathrm{~B}$ ) The time of $\mathrm{HV}$ development is unclear but fitting into her shoes became increasingly difficult in recent months prior to clinic visit. Her reducible HV was dominated by pain-free adduction, with flexible asymptomatic hallux malleus (HM) without EHL bowstringing on exam. Her HV was classified as Type 2A HV-adduction component with flexion at hallux IPJ - under the Clinical Practice Guideline of First Metatarsophalangeal Joint Disorder Panel Classification. ${ }^{1}$ The patient had tried taping and shoe gear changes previously, which provided limited relief.

\section{Surgical Technique}

Right HV correction was performed with Mini TightRope ${ }^{\circledR}$ (Arthrex Inc., Naples, FL) system, an implanted fixation device with suture and button (FiberWire ${ }^{\circledR}$, Arthrex Inc.). A dorsal bunionectomy incision centered over $1^{\text {st }}$ MTPJ was used. Standard bunion dissection was achieved with linear medial capsulotomy was used. Guide wires and Mini TightRope ${ }^{\circledR}$ were placed as described in technique described by Gerbert, et al., ${ }^{6}$ with drill holes being placed parallel to weight-bearing surface. Buttons were applied such that the distal and proximal anchors lie within the same transverse plane. (Fig. 2A and $2 \mathrm{~B}$ ) Surgical site was closed in layers and skin was closed using non-absorbable suture.

\section{Postoperative Course}

Intraoperative correction of $\mathrm{HV}$ was achieved and HM had appeared to improve after HV correction. (Fig. 2A and 2B) Patient was allowed to heel-touch weightbear after surgery with use of postoperative shoe. Correction was maintained at 2-week follow up. Sutures were removed at 2-week postoperatively and she was transitioned to running shoes with activities as tolerated. 




Figure 2A and 2B Two week postoperative radiograph of right foot. A Dorsal plantar view (DP) shows $6^{\circ}$ hallux abduction angle. (A) The lateral radiographs shows suture anchors placed in transverse plane parallel to weightbearing surface. Hallux malleus (HM) is reduced after correction of HV with TSD. (B) There is radiographic artifact in calcaneus.
At the 4 week postoperative visit, she began to develop mild recurrence of HV with mild HM. (Fig. $3 \mathrm{~A}$ and $3 \mathrm{~B}$ ) Distal suture anchor seems to be shifted dorsally (Fig. 3B) as a result of rotation caused by recurrence of mild HV. EHL became bowstrung over first ray on exam. During subsequent follow up visits, new plantar first metatarsal pain and symptomatic tightness over the EHL were described, while mild recurrence of $\mathrm{HV}$ remained clinically reducible.

Strapping and tapping of HM were tried postoperatively. Physical Therapy was not pursued as gait was asymptomatic and range of motion through gait was normal. Seven months postoperatively, she continued to have sub first metatarsal head pain with progression of EHL bowstringing. Subsequently, EHL lengthening procedure was performed. HM and HV corrected with this procedure and the TSD did not show any laxity or displacement. Skin was closed using absorbable suture. There were no postoperative complications and transition to athletic shoe gear was achieved two weeks postoperatively. Seven months after EHL lengthening, her right foot continues to be asymptomatic and she has returned to her baseline level of activity - performing ADLs and playing tennis. (Fig. 4A and 4B)

\section{Discussion}

There are currently no large case reports or long-term studies with use of TSD for HV correction. Case studies using various TSD systems have shown adequate HV correction without complications. $6,7,9$

Postoperative progression of EHL contracture caused worsening of HM and recurrence of HV. However, after EHL lengthening, TSD realigned HV deformity without other manipulations or procedures. In retrospect, EHL lengthening or transfer to correct for the Type 2A HV might have prevented development of $\mathrm{HM}$, although these procedures are not indicated for a Type $2 \mathrm{~A} \mathrm{HV}{ }^{1}$ 


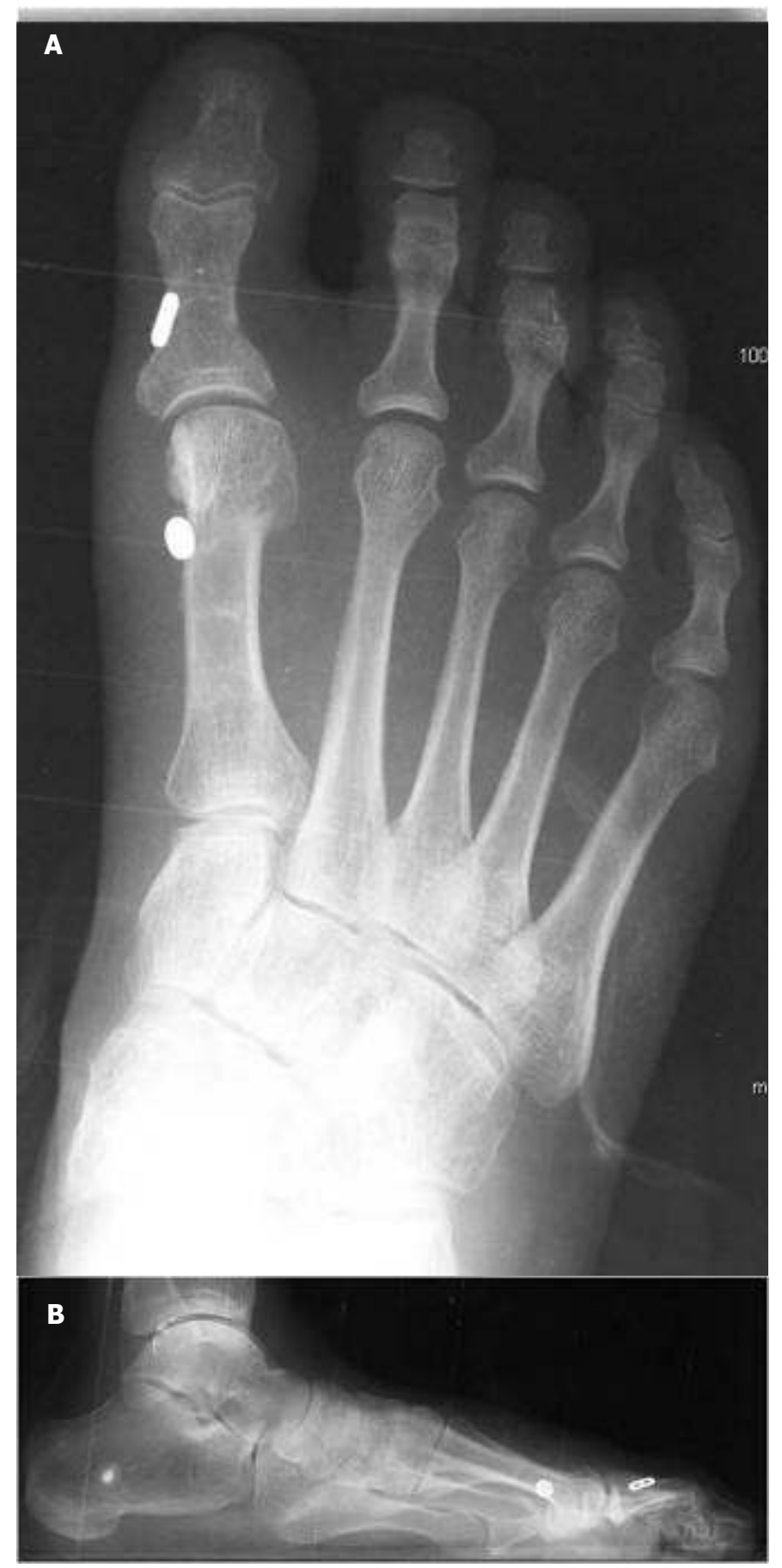

Figure 3A and 3B Four week postoperative radiograph of right foot. The dorsal plantar view showing $1.5^{\circ}$ hallux abduction Angle. Distal suture anchor rotated within frontal plane. (A) The lateral view shows the distal suture anchor more superior, secondary to rotation of proximal phalanx with recurrence of HV and dorsiflexion at first MTPJ from the hallux malleus. (B) Again, radiographic artifact is seen in the calcaneus.
Use of TSD remains a viable option for $\mathrm{HV}$ correction, when 1). Patient's bone stock is adequate, 2). Patient's first MTPJ is absent of arthritis or has low-grade arthritis, 3). Patient's tendons about the first MTPJ, is not the deforming force. A patient with the aforementioned criteria, presenting with a reducible, flexible $\mathrm{HV}$ with only transverse plane deviation is most appropriate for $\mathrm{HV}$ correction with the described TSD technique. In the senior author's experience (B.W.), TSD provides more control over the amount HV correction and is technically easier than soft tissue transfers or osteotomies.

It is unclear if progression of the mild sagittal plane deviation could have been prevented with more aggressive bandaging or aggressive range of motion with physical therapy. The technique that was used corrected the adduction deviation of a flexible Type $2 \mathrm{~A} \mathrm{HV}$, but the TSD could not prevent deviations in other planes. Application of TSD to correct for multiplanar correction has yet to be described. Possible biplanar HV correction using TSD may be considered. This would require placement of the first metatarsal button more plantarly than the proximal phalanx button, with placement of suture drill holes remaining parallel to the weight-bearing surface. Cadaveric studies of multiplanar correction with TSD will be required prior to clinical applications.

\section{References}

1. Vanore JV, Christensen JC, Kravitz SR, Schuberth JM, Thomas JL, Weil LS, Zlotoff HJ, Couture SD. Diagnosis and treatment of first metatarsophalangeal joint disorders. Section 3: Hallux Varus. J Foot Ankle Surg 2003 42: 137-142. [ubMed]

2. Bevernage BD, Leemrijse T. Hallux Varus: Classification and treatment. Foot Ankle Clin N Am. 2009. 14: 51-65. [pubMed] 3. Lagaay PM, Hamilton GA, Ford LA, Williams ME, Rush SM, Schuberth JM. Rates of revision surgery using Chevron-Austin osteotomy, Lapidus arthrodesis, and closing base wedge osteotomy for correction of hallux valgus. J Foot Ankle Surg. 2008 47: 267-272. [PubMed]

4. Leemrijse T, Hoang B, Maldague P, Docquier PL, Bevernage BD. A new surgical procedure for iatrogenic hallux varus: Reverse transfer of the abductor hallucis tendon A report of 7 case. Acta Orthop Belg 2008 74: 227-234. [PubMed] 5. Lau JTC, Myerson MS. Technique Tip: Modified split extensor halluces longus tendon transfer for correction of hallux varus. Foot Ankle Int 2002 23: 1138-1140. [pubMed] 


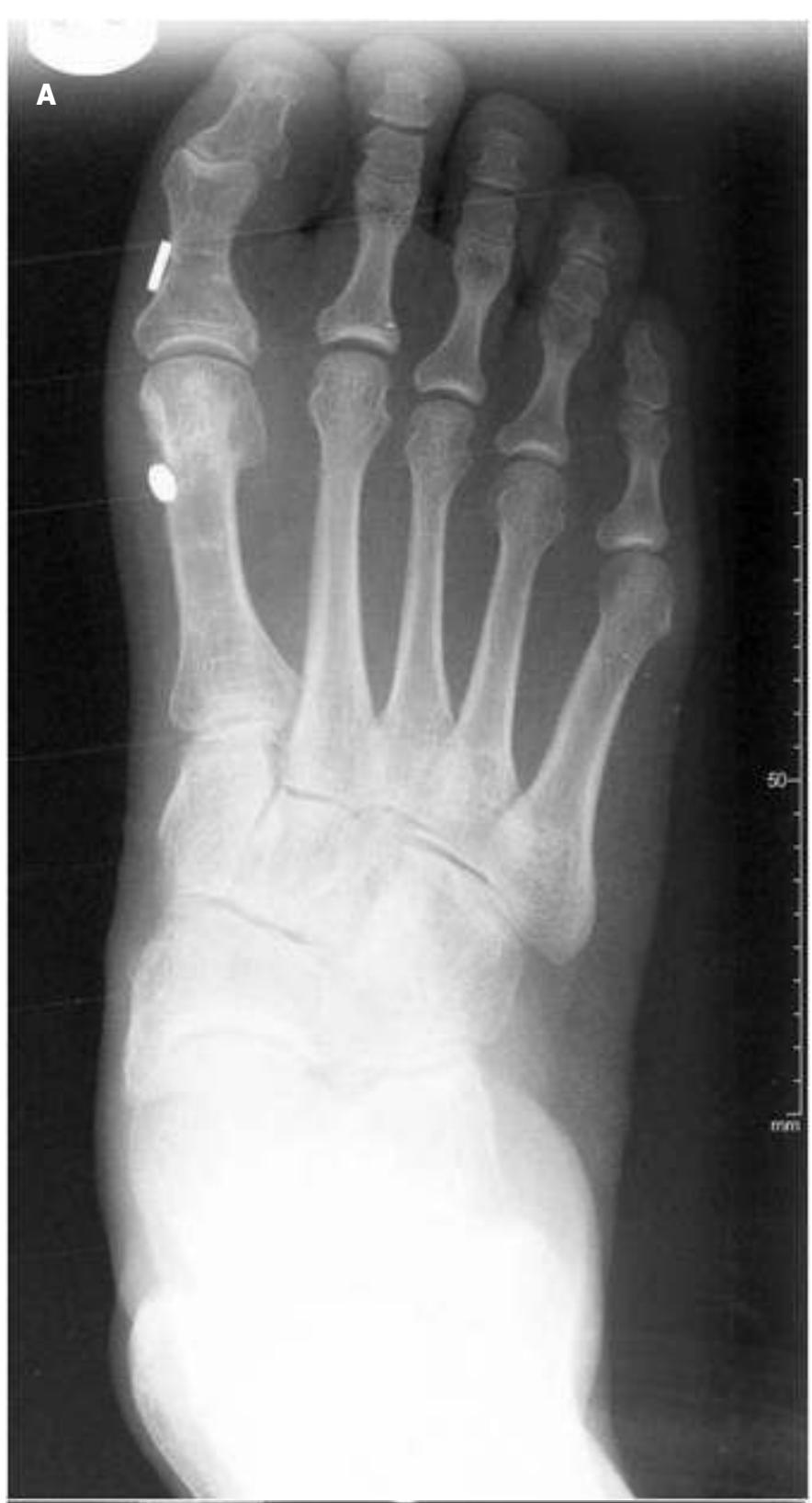

6. Gerbert J, Traynor C, Blue K, Kim K. Use of the Mini TightRope for correction of hallux varus deformity. J Foot Ankle Surg 2011 50: 245-251. [PubMed]

7. Pappas AJ, Anderson RB. Management of acquired hallux varus with an endobutton. Tech Foot Ankle Surg 2008 7: 134138. [Website]

8.Skalley TC, Myerson MS. The operative treatment of acquired hallux varus. Clin Orthop Relat Res 1994 306: 183-191. PubMed]

9. Labovitz JM, Kaczander BI. Traumatic hallux varus repair utilizing a soft-tissue anchor: A case report. J Foot Ankle Surg 2000 39: 120-123. [PubMed]

10.Naqvi GA, Shafqat A, Awan N. Tightrope fixation of ankle syndesmosis injuries: Clinical outcome, complications and technique modification. Injury 2011: doi:10.1016/j.injury.2011.10.002 [PubMed]

11.Willmott HJS, Singh B, David LA. Outcome and complications of treatment of ankle diastasis with tightrope fixation. Injury 2009 40: 1204-1206. [PubMed]

12. Coetzee JC, Ebeling P. Treatment of syndesmoses disruptions: a prospective, randomized study comparing conventional screw fixation vs TightRope® fiber wire fixationmedium term results. South African Orthopaedic J 2009 8: 3237. $[\underline{\mathrm{PDF}}]$

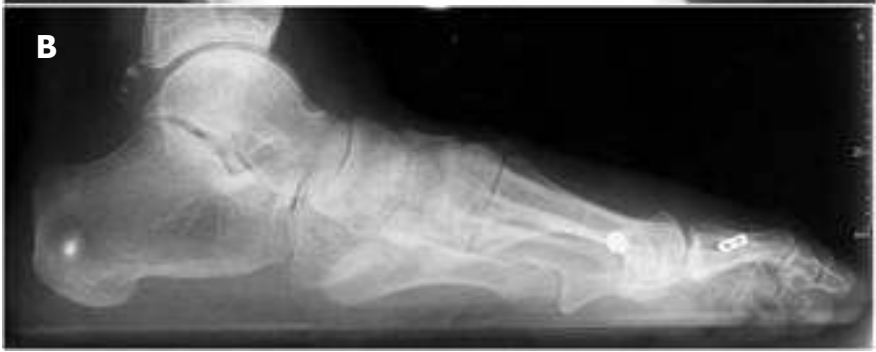

Figure 4A and 4B Seven months after extensor hallucis longus (EHL) tendon lengthening. The dorsal plantar (DP) view shows $7^{\circ}$ hallux abduction angle. (A) The lateral radiograph shows the rotation of proximal phalanx reduced after EHL lengthening. Radiographic artifact is again seen in the calcaneus. (B) 